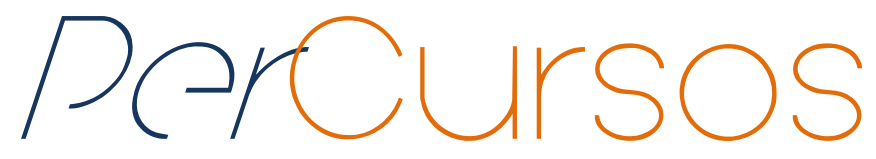

\title{
Projeto éfeito de papel: trabalho, renda e identidade entre usuários da rede de atenção à saúde mental ${ }^{1}$
}

\section{Resumo}

O presente artigo, a partir da discussão mais geral sobre o movimento conhecido como Reforma Psiquiátrica, objetiva discutir sobre o projeto "éfeito de papel" (EP), realizado pelo Instituto Franco Basaglia através da promoção de oficinas de geração de trabalho e renda para usuários da rede de saúde mental da cidade do Rio de Janeiro. Trata-se de observar de que maneira esse projeto buscou atender umas das principais demandas de usuários e familiares no que se refere à inserção no mercado de trabalho. Essa pesquisa foi desenvolvida por meio de trabalho etnográfico, pesquisa bibliográfica, consulta documental e entrevistas semiestruturadas. Observamos que ações dirigidas como o "projeto éfeito de papel", promovem novas possibilidades de (re)construção social da identidade dos usuários da rede CAPS. E, ainda, como as práticas artesanais desenvolvidas nas oficinas do EP podem ser pertinentes a corroborar para as transformações do imaginário social das representações acerca dos "sujeitos em sofrimento psíquico".

Palavras-chave: Reforma Psiquiátrica. Saúde Mental. Trabalho e Renda. Identidade.

\author{
Giselli Avíncula Campos \\ Mestre em Ciências Sociais pela \\ Universidade Federal Rural do \\ Rio de Janeiro - UFRRJ. \\ Professora de Sociologia da \\ Secretaria de Estado de \\ Educação do Rio de Janeiro - \\ SEEDUC/RJ. \\ Brasil \\ g_avincula@hotmail.com
}

\section{Para citar este artigo: \\ CAMPOS, Giselli Avíncula. Projeto éfeito de papel: trabalho, renda e identidade entre usuários da rede de atenção à saúde mental. Revista PerCursos, Florianópolis, v. 18, n.36, p. 233 - 258, jan./abr. 2017.}

\section{DOI: $10.5965 / 1984724618362017233$}

http://dx.doi.org/10.5965/1984724618362017233

\footnotetext{
1 Esta pesquisa é parte da dissertação de mestrado "Amassado, apertado e pincelado com as cores da primavera: identidades em (re)construção em uma oficina de produção artesanal nos centros de atenção psicossocial"defendida em 2014, que teve apoio da CAPES.
} 


\title{
Éfeito de papel project: work, income and identity of users of mental health care network
}

\begin{abstract}
This article, based on the more general discussion about the movement known as Psychiatric Reform, aims to discuss the "paper effect" $(E P)$ project carried out by the Franco Basaglia Institute through the promotion of workshops to generate work and income for users of Mental health network of the city of Rio de Janeiro. The idea is to observe how this project sought to meet one of the main demands of users and family members regarding the insertion in the job market. This research was developed through ethnographic work, bibliographical research, documentary consultation and semi-structured interviews. We observe that actions directed as the "paper-based project" promote new possibilities for social (re) construction of the identity of users of the CAPS network. And yet, how the artisanal practices developed in the workshops of the EP may be pertinent to corroborate for the transformations of the social imaginary of the representations about the "subjects in psychic suffering".
\end{abstract}

Keywords: Psychiatric Reform. Mental Health. Work and Income. Identity. 


\section{Introdução}

O filósofo Michel Foucault, em sua obra História da Loucura na Idade Clássica (2010), apresenta a concepção e a transformação do conceito de "loucura" desde a Renascença à Modernidade. Apresenta na obra referida a longa história da separação entre razão/desrazão e a emergência da loucura como efeito, na Modernidade, da “depuração” das diferentes figuras da desrazão. Além disso, o autor nos revela histórica e culturalmente, o surgimento da Psiquiatria como especialidade da medicina dedicada ao fenômeno da "loucura", empoderada para formulação de paradigmas teóricos e práticos para o cuidado da "doença mental", que passa a ser o objeto de estudo da psiquiatria.

A Psiquiatria, então, realiza a "psiquiatrização da loucura" em fins do século XVIII e no século XIX, e transforma o espaço do internamento, antes de exclusão e degredo da população desviante (BECKER, 2008) em espaço de controle, repressão, segregação e medicalização.

Para melhor compreender o termo da "psiquiatrização", retomemos algumas construções conceituais e teóricas em diversas obras de Foucault (1977; 1999; 2000; 2007; 2010). Em A História da Loucura na Idade Clássica (2010), o filósofo apresenta a metamorfose das representações sociais da "loucura" desde a era renascentista à moderna, reconstruindo a significação que, em diferentes períodos da humanidade, cada sistema cultural atribuiu ao fenômeno da "loucura". Na obra Poder Psiquiátrico (FOUCAULT, 2007), analisa como os discursos, a ciência e o poder direcionaram as relações com a "loucura", estabelecendo relações de controle nas quais a Psiquiatria se torna responsável pela "loucura" na figura do médico psiquiatra, detentor do saber médico-científico, e do manicômio como local exclusivo de tratamento e cura.

Dessa forma, a "Loucura" é um "dispositivo", entendendo o conceito como ferramenta analítica desenvolvida por Foucault em a História da Sexualidade l: a vontade de saber ${ }^{2}$, como um complexo que reúne discursos, instituições, práticas, conjuntos arquitetônicos, legislação, ações administrativas, tratados científicos, discussões epistemológicas de cunho filosófico e moral. Foucault resume que "o dispositivo é a rede

2 Ver obra FOUCAULT, Michel. História da Sexualidade I: a vontade de saber. Rio de Janeiro: Graal, 1999. 
que se pode estabelecer entre estes elementos" (FOUCAULT, 2000, p. 244).

Os aspectos sobre a "loucura" foram construídos por saberes, práticas e instituições que a transformaram num campo do conhecimento científico e de intervenção social. Nesse sentido, o paradigma psiquiátrico se tornou um "dispositivo" de controle médico-disciplinar sobre saúde e comportamento, regulado pela Psiquiatria e outras instituições, como Igreja, Família, Direito e Estado.

Portanto, a psiquiatrização é "a produção e a terapeutização da doença mental a partir de um conjunto bem delimitado de estratégias de poder" (CAPONI, 2009, p. 100), isto é, uma série de entendimentos, discursos, técnicas e procedimentos que instauram a Psiquiatria como Instituição Social a deter o exclusivo conjunto de saberes, poderes e práticas médicas reconhecidos, aceitos e sancionados como legítimos sobre a concepção, tratamento e cura da "loucura", tornando-a "doença mental".

No entanto, paralelamente, foi se desenvolvendo a crítica e o questionamento a este modelo psiquiátrico instituído. Uma dessas críticas ocorreu na Europa, após a Segunda Guerra, através de psiquiatras que questionaram e adotaram ações, objetivando a transformação ou até mesmo extinção dos hospitais psiquiátricos existentes. No Brasil, a crítica mais sistemática com a formação de coletivos, inspirada pelas experiências europeias, inicia-se no final da década de 70, no contexto da redemocratização, com a mobilização dos profissionais da saúde mental através do Movimento dos Trabalhadores em Saúde Mental.

Esses movimentos que se centraram contra o paradigma psiquiátrico vigente foram denominados de Reforma Psiquiátrica (RP), ${ }^{3}$ e se constituem como um processo social complexo de saberes e práticas substitutivos ao saber psiquiátrico tradicional e à centralidade do hospital - que segrega, encarcera e diagnostica as pessoas como

\footnotetext{
${ }^{3}$ A Reforma Psiquiátrica é compreendida por um múltiplo movimento de desconstrução do modelo hospitalar de assistência e de construção de uma rede substitutiva para a reabilitação clínica e psicossocial em bases comunitárias e territoriais. Prosseguiu na revisão dos códigos legislativos sobre a condição jurídico-política dos pacientes psiquiátricos; na formulação, implantação e acompanhamento de políticas públicas de saúde mental, em seus princípios e diretrizes, a organizar e gerir os serviços substitutivos de assistência; reorientar os procedimentos epistemológicos, científicos, tecnológicos e terapêuticos; capacitar a atuação dos profissionais nas práticas de cuidado e atenção aos usuários dos novos dispositivos de assistência à saúde mental.
} 
"doentes mentais", privando-as do convívio e de sua reabilitação nos diferentes espaços da vida no social.

É importante destacar que a Reforma Psiquiátrica, como movimento, veio transpor o discurso médico-psiquiátrico fundado no manicômio e na cura da doença mental, para discussões interdisciplinares em prol da promoção da saúde mental. Todavia, o campo da Reforma - em torno da ruptura do modelo hospitalocêntrico no cuidado do louco e no entendimento da loucura - não se caracteriza como objeto monolítico, e sim por um espaço tenso que agrega multiplicidade de atores e disputa de discursos. Os embates discursivos, políticos e técnico-científico entre os atores da Reforma Psiquiátrica não serão priorizados aqui. Por objetivo desse trabalho, indicaremos a categoria "Reforma Psiquiátrica" como um movimento complexo e heterogêneo pela mudança do paradigma epistemológico-assistencial e consolidação de serviços substitutivos em saúde mental.

Os ideais da Reforma Psiquiátrica se referem ao desafio de consolidar diretrizes e políticas públicas rompendo com o modelo histórico centrado no hospital como forma de assistência, propondo a construção de uma rede de novas instituições de atenção à saúde mental. Aos poucos, esses discursos se voltaram para a questão da "cidadania como valor fundante e organizador deste processo" (TENÓRIO, 2002, p. 28), na tentativa de transformar os sujeitos egressos de longa internação psiquiátrica em usuários dos serviços ${ }^{4}$ de atenção à saúde mental, que exercem o direito à cidade e a liberdade civil com base comunitária para a reabilitação psicossocial. ${ }^{5}$

A noção de "saúde mental" demandou reformulações epistemológicas, dos serviços de assistência, da revisão jurídica referente aos direitos de cidadania e autonomia dos usuários, e da desestigmatização da figura do "louco" perigoso, alienado, irresponsável e incapacitado impregnados no imaginário social. Esses pressupostos incorporados à "saúde mental" tornam-se Política Pública de Estado no Brasil através da

\footnotetext{
${ }^{4}$ A terminologia "usuários dos serviços de saúde mental" em lugar de louco, doente mental e pacientes confere a ideia de protagonismo e autonomia do sujeito que busca assistência e promoção da saúde mental. A terminologia é fundamental no processo de reconstrução das representações sobre a loucura.

${ }^{5}$ A noção de atenção psicossocial foi construída a partir do movimento da Reforma Psiquiátrica brasileira iniciada em fins da década de 1970, que buscou pela reorientação dos serviços de assistência psiquiátrica.
} 
regulamentação da Lei da Reforma Psiquiátrica - sob o n 10.216/2001, conhecida por Lei Paulo Delgado - e inúmeras portarias ministeriais que formalizaram as bandeiras do movimento da Reforma.

Nesse sentido, para superar o histórico autoritário e disciplinador, a Reforma Psiquiátrica produziu novos conceitos, novas funções e novas percepções sobre a "loucura" relacionando-as à concepção de "saúde mental" em detrimento da noção de "doença mental".

Entre tantos atores envolvidos com o movimento da Reformar Psiquiátrica, discutiremos nesse artigo o Instituto Franco Basaglia (IFB), que se trata de uma organização da sociedade civil, surgida em 1989 para discutir os novos paradigmas de atenção à saúde mental. Ao longo de sua existência, foram desenvolvidos inúmeros projetos em parceria com entes estatais, visando à autonomia e reinserção social dos sujeitos que vivenciam o sofrimento psíquico. Nesse artigo, privilegiaremos o "Projeto éfeito de papel: implantação de polos de produção artesanal na rede de saúde mental da cidade do Rio de Janeiro", criado no ano de 2009, sob o patrocínio da PETROBRÁs em parceria com o Governo Municipal. Esse projeto propunha atender uma das principais demandas dos usuários e familiares da rede de atenção psicossocial: a inserção no mundo do trabalho.

Para tratar dessas questões foi realizado o trabalho etnográfico em duas oficinas de produção artesanal, desenvolvidas em dois diferentes Centros de Atenção Psicossocial (CAPS), nos anos de 2012 e 2013; análise dos relatórios de campo de bolsistas do projeto e entrevistas semiestruturadas com os diferentes atores envolvidos no campo de trabalho.

\section{Antecedentes da Reforma Psiquiátrica}

As contribuições de Osório Cesar e, sobretudo, de Nise da Silveira, médicos psiquiatras brasileiros que introduziram, na primeira metade no século $\mathrm{XX}$, o uso da arte em ambientes hospitalares, já demonstravam o questionamento, ainda que isolado, da lógica manicomial, lançando alguns fundamentos à concepção e elaboração das diretrizes da Reforma Psiquiátrica no campo da arte, cultura e diversidade. 
Antes do movimento da Reforma, destaca-se o pioneirismo presente na experiência do ateliê terapêutico do Setor de Terapia Ocupacional, criado pela Dr ${ }^{\mathrm{a}}$ Nise da Silveria, no antigo Centro Psiquiátrico Pedro II do Engenho de Dentro. Tal atividade tornou-se atrativa tanto ao campo da psicanálise, através da figura do renomado psicanalista Carl Gustav Jung, que inspirou e incentivou Nise a prosseguir com esse trabalho; quanto ao público ligado às artes - artistas e críticos de arte, como Mário Pedrosa (BEZERRA JR, 2011).

O movimento da Reforma Psiquiátrica brasileira foi fortemente influenciado pela experiência estética e terapêutica realizada no Setor de Terapia Ocupacional, dirigido pela Dra Nise da Silveira na década de 1940. E com vistas à transformação da identidade de "doente mental", o movimento da Reforma tem enaltecido a vertente de uma dimensão sociocultural através da noção de arte, cultura e diversidade cultural, combatendo a "psiquiatrização" destes sujeitos, dando ensejo às estratégias de transformar as relações sociais e o lugar social da "loucura" pautados na alteridade. Isso requer dizer que a ideia da diversidade relaciona-se com o diálogo e aceitação da diferença, visando produzir uma rede de comunicação e solidariedade a fim de que a individualidade viabilize-se pela perspectiva da coletividade (AMARANTE; COSTA, 2012).

\section{Movimento dos Trabalhadores da Saúde Mental: a origem e o esteio da} Reforma Psiquiátrica Brasileira

(...) Movimento dos Trabalhadores em Saúde Mental, por nós considerado o ator e sujeito político fundamental no projeto da reforma psiquiátrica brasileira. É o ator a partir do qual originalmente emergem as propostas de reformulação do sistema assistencial e no qual se consolida o pensamento crítico ao saber psiquiátrico. (AMARANTE, 1995', p. 51)

O que veio a ser conhecido como movimento da Reforma Psiquiátrica no Brasil teve início, como anteriormente mencionado, com o movimento da Reforma Sanitária na década de 70 do século XX. Esse movimento, que se desenvolveu no processo de 
redemocratização do país, reivindicou políticas públicas de saúde inclusivas, equitativas, democráticas, tendo em vista a abertura e livre acesso da população à assistência e gestão da saúde.

Foi no contexto dos debates sobre a Reforma Sanitária que no Rio de Janeiro, em abril de 1978, houve a greve dos profissionais das unidades do DINSAM ${ }^{6}$ (Divisão Nacional de Saúde Mental), após a demissão de 260 estagiários e profissionais da saúde devido às denúncias de três médicos - bolsistas do Centro Psiquiátrico Pedro II (CPPII). Estes médicos registraram, no livro de ocorrências da Unidade, as irregularidades do hospital referentes às condições e situação dos contratos de trabalho, à assistência e desumanização dos serviços dirigidos à população.

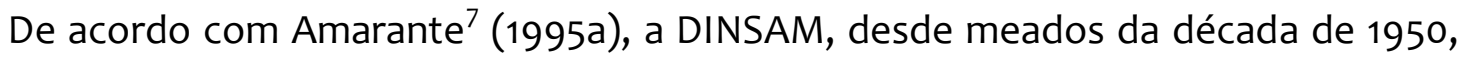
não realizava concurso público, apenas contratando, a partir de 1974, profissionais graduados ou estudantes universitários como bolsistas. Estes trabalhavam em condições precárias, com constante assédio moral e expostos à violência física que atingia também profissionais mas, sobretudo, os internos destas instituições. As denúncias gravitavam em agressão, estupro, trabalho escravo e mortes não esclarecidas.

Essa denúncia por parte dos bolsistas do CPPII instaurou a chamada "Crise do DINSAM", o qual diante da denúncia dos jovens médicos, respondeu arbitrariamente com a demissão sumária dos bolsistas e profissionais. Em contrapartida, foi deflagrada a greve dos profissionais da saúde mental. Esta foi a primeira greve de servidores públicos na vigência do regime ditatorial. A paralisação acabou mobilizando profissionais de outras

\footnotetext{
${ }^{6}$ Órgão do Ministério da Saúde responsável pela formulação das políticas públicas em saúde mental. As quatro unidades do DINSAM eram no Rio de Janeiro: Centro Psiquiátrico Pedro II, o atual Instituto Municipal Nise da Silveira; Hospital Pinel hoje como Instituto Municipal Phillipe Pinel; Colônia Juliano Moreira que passou a chamar-se Instituto Municipal de Assistência à Saúde Juliano Moreira, e o Manicômio Judiciário Heitor Carrilho, atualmente o Hospital de Custódia e Tratamento Psiquiátrico Heitor Carrilho. Todos eram administrados pelo Governo Federal desde sua criação; as três primeiras unidades foram municipalizadas, de acordo com os preceitos do Sistema Único de Saúde; já o último, foi entregue à administração estadual do Rio de Janeiro.

7 Paulo Amarante é médico psiquiatra e se tornou um dos pioneiros do movimento brasileiro de Reforma Psiquiátrica, tanto como um dos protagonistas deste movimento, quanto como pesquisador da saúde mental com inúmeras publicações sobre a trajetória da Reforma Psiquiátrica brasileira e suas dimensões basilares.
} 
unidades e o apoio do Movimento de Renovação Médica ${ }^{8}$ (REME) e do Centro Brasileiro de Estudos de Saúde ${ }^{9}$ (CEBES) tomou praticamente toda a extensão do país (FLEURY, 1997). Paralelamente, a histórica greve dos metalúrgicos do $A B C$, em 1979, eclodiu nesse contexto, desencadeando como resposta do governo a promulgação, pelo Presidente Ernesto Geisel, de um decreto que proibia qualquer greve nos setores considerados essenciais.

É neste contexto de luta sindical que, posteriormente, após periódicas reuniões e assembleias com intensas discussões nos espaços dos sindicatos, entre outras entidades da sociedade civil, constituiu-se o Movimento dos Trabalhadores da Saúde Mental $(\mathrm{MTSM})^{10}$. Nas palavras de Amarante:

Atuando sob sua própria legenda ou no interior de outros espaços de representação (CEBES, Sindicatos, Partidos Políticos, Associações, Rede de Alternativas à Psiquiatria, Sociedade de Psicossíntese, etc.), o MTSM torna-se o primeiro e mais importante ator de renovação no campo da saúde mental, que vai estabelecer uma agenda para o setor que, sob o título de Reforma Psiquiátrica, introduz a estratégia da desinstitucionalização no âmbito das políticas públicas. (AMARANTE, 1997, p. 164)

O MTSM constituiu-se como um locus de discussões e formulações de propostas visando à mudança do paradigma de assistência psiquiátrica. Para isso, sistematizava

${ }^{8}$ O Movimento de Renovação Médica, o REME, surgiu no Rio de Janeiro, no final da década de 1970, juntamente com outros movimentos de apoio à redemocratização do país e do sanitarismo. Organizou-se como oposição sindical às tradicionais lideranças médicas descompromissadas com os interesses de suas bases, e conquistou as mais importantes entidades sindicais da categoria. O REME, como movimento social, assumiu dupla função, tanto como movimento popular em saúde atrelado à Reforma Sanitária , quanto movimento médico centrado na regulação da profissão e da consciência trabalhista. [SANTOS, 2004, apud Campos (1988), Escorel (1995 e 1999) e Gerschman (1995)].

${ }^{9}$ O Centro Brasileiro de Estudos de Saúde é uma entidade civil, de âmbito nacional, criada em 1976, no contexto do regime de exceção no Brasil. Sua bandeira é a luta pela democratização da sociedade e pela defesa dos direitos sociais, especificamente o direito universal à saúde. Reúne ativistas, lideranças, pesquisadores, professores, profissionais e estudantes, estabelecendo parcerias com movimentos sociais e organizações da sociedade civil na luta pela saúde. O Cebes produz e divulga informações, conhecimentos e análises críticas em saúde através de publicações acadêmicas variadas e mantendo, ainda nos dias atuais, a Revista Saúde em Debate. (http://cebes.com.br/) Acesso em 30 jun. 2014.

${ }^{10}$ MTSM é um movimento plural. Inicialmente formado por trabalhadores que integravam os quadros do serviço público, e por mais tarde agregar, entre seus integrantes, as associações de familiares, sindicalistas, membros de associações de profissionais e pacientes psiquiátricos com histórico de longa internação. 
diversas informações, organizava encontros reunindo trabalhadores, associações de classe, entre outras entidades.

As reivindicações do MTSM transitavam desde a formalização e regularização do quadro de funcionários das unidades do DINSAM, da atuação profissional e funcional dos bolsistas, das condições de trabalho e salário dos profissionais da saúde mental, bem como dirigia críticas ao modelo centrado estritamente no hospital, questionando as práticas de eletrochoque, lobotomia e coma insulínico como técnicas hegemônicas e consagradas na assistência psiquiátrica no Brasil. Essas técnicas cada vez mais se destacavam pela ineficiência terapêutica; o estigma, a persistência e agravamento dos sintomas apontavam os manicômios como locais de marginalização, doença e morte.

Aos poucos, a ideia de exercício da cidadania fundada em direitos e deveres por parte dos pacientes psiquiátricos passou a fundamentar o projeto da luta antimanicomial. Ao perceber que não seria possível pensar nessa proposta a partir das instituições hospitalares, surgiu como proposta a ideia de "desinstitucionalização", nos moldes da experiência do movimento da Psiquiatria Democrática Italiana.

Paulo Amarante (1995b), um dos atores sociais vinculados ao MTSM, assim define a noção de desinstitucionalização:

A desinstitucionalização é este processo, não apenas técnico, administrativo, jurídico, legislativo ou político; é, acima de tudo, um processo ético, de reconhecimento e uma prática que introduz novos sujeitos de direito e novos direitos para os sujeitos. De uma prática que reconhece, inclusive, o direito das pessoas mentalmente enfermas em terem um tratamento efetivo, em receberem um cuidado verdadeiro, uma terapêutica cidadã, não um cativeiro. Sendo uma questão de base ética, o futuro da reforma psiquiátrica não está apenas no sucesso terapêutico-assistencial das novas tecnologias de cuidado ou dos novos serviços, mas na escolha da sociedade brasileira, da forma como vai lidar com os seus diferentes, com suas minorias, com os sujeitos em desvantagem social. (AMARANTE, 1995b, p. 494)

Neste sentido, os debates acerca da necessidade de repensar as práticas psiquiátricas colocaram o processo da desinstitucionalização do modelo de atenção à 
saúde mental na centralidade da agenda de lutas.

Entendemos que a desinstitucionalização do paradigma psiquiátrico tradicional, conforme aponta Amarante (1995a), é o cerne que sustenta o movimento da Reforma Psiquiátrica. Esta, sendo um processo complexo, não se restringe às transformações das práticas do cuidado e técnicas terapêuticas dirigidas aos pacientes internados em asilos; tampouco à criação de serviços substitutivos de assistência à saúde mental e formação de equipes multiprofissionais. O movimento da Reforma quer desinstitucionalizar o aparato epistemológico que inclui "saberes e práticas" específicas no campo da saúde mental; bem como o "lugar social" destinado ao "louco" e à "loucura".

Desta forma, retirado o manto de cientificidade da psiquiatria, torna-se possível percebê-la como instrumento técnico-científico de poder ou como saber e prática disciplinares e normalizadoras. A denúncia da realidade dos hospitais psiquiátricos tornou possível verificar sua função mais custodial que assistencial, mais iatrogênica que terapêutica, mais alienadora que libertadora. Se por um lado a psiquiatria deixava de ser questão exclusiva dos técnicos para tornar-se uma questão que diz respeito à toda a sociedade, por outro, o objeto da psiquiatria deixava de ser a doença - contra a qual ela se mostrara impotente - para tornar-se o sujeito da experiência do sofrimento. Como consequência, em torno do debate da Reforma Psiquiátrica passava a existir um dos mais expressivos e atuantes movimentos sociais, com uma proposta radical de transformação do setor, que tem merecido um destaque sem igual na história da saúde pública do país. Assim, antes de mais nada, é preciso explicitar o que se está entendendo, ou construindo, sob o título de Reforma Psiquiátrica. (AMARANTE, 1997, p. 165)

A desistitucionalização do modelo centrado nos hospitais e das técnicas terapêuticas de tratamento desumano e marginal são algumas facetas deste processo da Reforma, conforme apontam Amarante e Costa (2012). Além da questão "teóricoconceitual" e "técnica-assistencial", há o desejo de operar a transformação das relações da sociedade com o "louco" e a "loucura" que perpassa outras dimensões: como a "jurídico-política", que é entendida pela revisão das legislações garantindo a autonomia através do exercício dos direitos civis e sociais; e a dimensão "sociocultural" que busca, através da expressão da arte e cultura, a transformação do imaginário social relacionado 
à "loucura" e da experiência do sujeito em "sofrimento psíquico".

(...) a Reforma Psiquiátrica da qual se está falando não diz respeito, exclusivamente, a medidas de caráter tecnocientífico ou organizacional. Reforma Psiquiátrica, neste contexto, é um processo permanente de construção de reflexões e transformações que ocorrem a um só tempo, nos campos assistencial, cultural, e conceitual. (...) neste contexto complexo, questionar-se quanto ao principal objetivo da Reforma Psiquiátrica, talvez fosse possível responder que seria poder transformar as relações que a sociedade, os sujeitos e as instituições estabeleceram com a loucura, com o louco e com a doença mental, conduzindo tais relações no sentido da superação do estigma, da segregação, da desqualificação dos sujeitos ou, ainda, no sentido de estabelecer com a loucura uma relação de coexistência, de troca, de solidariedade, de positividade e de cuidados. (AMARANTE, 1997, p. 165)

As quatro dimensões classificadas e conceituadas por Amarante e Costa (2012) representam a tentativa de descrever a complexidade do processo que desembocou no que hoje é denominado Reforma Psiquiátrica. Desta forma, teremos, a seguir, considerações a respeito da RP como resultado de diferentes e heterogêneas ações coletivas que podemos enquadrar na categoria de "novos movimentos sociais", com reivindicações dirigidas ao campo da saúde mental.

O movimento da Reforma Psiquiátrica como uma expressão dos "novos movimentos sociais"

A primeira questão ao se lidar com os novos movimentos sociais é a seguinte: sob que aspectos são eles "novos"? (...) O fato particularmente novo e marcante nos movimentos sociais que emergiram na América Latina durante os últimos vinte anos é que - talvez pela primeira vez este momento totalizante se encontre ausente ou, pelo menos, seriamente questionado. As mobilizações populares não mais se baseiam num modelo de sociedade total ou na cristalização, em termos de equivalência de um único conflito que divida a totalidade do social em dois campos, mas numa pluralidade de exigências concretas, conduzindo a uma proliferação de espaços políticos. (LACLAU, 1986)

O final da década de 1980 e início de 1990 destacaram-se em importância histórica 
para a sociedade brasileira devido ao processo de restauração política da democracia. Em 1988, foi promulgada a Constituição Federal através de um processo que contou com a participação popular expressa pela sociedade civil organizada, que interferiu ativamente nos debates, subsidiando a escrita do texto constitucional. Já o ano de 1989, marca o retorno das eleições diretas para presidente da República. No ano de 1990, foi regulamentado, através da Lei $\mathrm{n}^{\circ}$ 8.080, o Sistema Único de Saúde - SUS. Esse sistema é fundado nos princípios de acesso universal, público e gratuito aos serviços de assistência à saúde, bem como na democratização da gestão pública através da gestão descentralizada e participativa instituída pela Constituição Federal de 1988.

O SUS procura assegurar a participação popular, por meio de organizações representativas, no processo de formulação e controle das políticas públicas em todos os níveis da gestão administrativa: municipal, estadual e federal. Nesse sentido, o período da redemocratização foi marcado pela emergência de "novos movimentos sociais", que se organizavam como sujeitos que empreendiam ações reivindicativas, propositivas e autônomas. A participação de diversos setores da sociedade se multiplicava por todo o país em torno da conquista, garantia e ampliação de direitos e do controle social. Maria da Glória Gonh (1995) avalia essa participação popular como expressão da soberania popular na construção de uma gestão democrática Estado-Sociedade no processo de formulação e implementação de políticas públicas. De acordo com Gonh:

A rearticulação da sociedade civil ocorrida no período [Constituição de 1988], foi acompanhada da elaboração de vários projetos de mudança social para o Brasil. A união das forças de oposição possibilitou a construção de propostas e frentes de lutas. Havia um clima de esperança, de crença na necessidade de retomada da democracia, da necessidade da participação dos indivíduos na sociedade e na política. Havia também a crença na força do povo, das camadas populares, quando organizadas, para realizarem mudanças históricas que outros grupos sociais não tinham conseguido realizar no passado. (GOHN, 1995, p. 113)

\footnotetext{
${ }^{11}$ Ver na obra de GOHN, Maria da Glória. Teorias dos movimentos sociais. Paradigmas clássicos e contemporâneos. São Paulo: Loyola, 1997. LACLAU, Ernesto. Os novos movimentos sociais e a pluralidade do social. Revista Brasileira de Ciências Sociais, n. 2, vol. 1, out.,1986. TOURAINE, Alain. Crítica da modernidade. Petrópolis: Vozes, 1998, que discorrem sobre as teorias dos movimentos sociais.
} 
Sobre o conceito de movimentos sociais, teceremos breves considerações teóricas. Este fenômeno social era associado apenas à organização e à ação dos trabalhadores em sindicatos e partidos políticos, tendo por base os conceitos de modos de produção, luta de classes e relações sociais de produção na ótica da teoria de Karl Marx (1982). Segundo Laclau (1986), a evidência de movimentos centrados nas questões da identidade, impulsionou autores como Allan Touraine e Manuel Castells a se debruçarem sobre as ações coletivas dos movimentos sociais, resultando em críticas sistemáticas do enfoque marxista da perspectiva de luta de classes, e assim se desenvolve a criação de uma teoria sociológica dos "Novos Movimentos Sociais", em que os sujeitos sociais passaram a ser vistos nas suas demandas específicas e pelo reconhecimento de suas diferenças. De acordo com Gohn (apud GOSS e PRUDENCIO, 2004), a tomada do Estado deixa de ser o objetivo primordial dos movimentos sociais, que passam por um processo de transformação na sua própria concepção, e suas demandas circulam nas requisições da sociedade civil pela garantia dos direitos sociais.

É nesse cenário histórico-político, da atuação dos movimentos sociais, que o deputado federal Paulo Delgado, do PT/MG, apresentou o Projeto de Lei 3.657/89, o PL Paulo Delgado, que ratificava o debate sobre a loucura, a doença mental, a assistência psiquiátrica e os manicômios problematizados pelo movimento da Reforma Psiquiátrica. O texto legislativo dispunha "Sobre a extinção progressiva dos manicômios e sua substituição por outros recursos assistenciais e regulamenta a internação psiquiátrica compulsória." 12

O PL Paulo Delgado foi importante para evidenciar a temática dos serviços de assistência psiquiátrica no debate nacional. Do período de tramitação até sua promulgação em 2001 - sob a forma de Lei $n^{\circ}$ 10.216/2001 -, o PL foi acompanhado por alguns acontecimentos que legitimaram a necessidade da sua aprovação, conforme elencado por Hendrich, (2007). Dentre eles, destacamos:

a) a realização de debates e eventos como a Conferência de Caracas, realizada em 1990, na Venezuela, que criou uma espécie de consenso entre os governantes latino-

\footnotetext{
${ }^{12}$ Projeto de Lei (PL) 3657/1989 de setembro de 1989, transformado na Lei Ordinária 10216/2001 em abril de 2001.
} 
americanos em torno de uma nova plataforma psiquiátrica (HENDRICH, 2007), a II Conferência Nacional de Saúde mental, que ocorreu em 1992, sob o tema "A reestruturação da atenção em saúde mental no Brasil: modelo assistencial e direito à cidadania", a qual se realizou em um momento em que se consolidavam experiências por todo o país, aprovações de leis estaduais e portarias ministeriais que possibilitavam a implantação de novos serviços e aumentavam a fiscalização dos hospitais, além do surgimento de diversas associações de usuários e familiares atuando ativamente pelo país (HENDRICH, 2007), e no ano de 1993, ocorre o I Encontro Nacional de Luta Antimanicomial, o I ENLA, que com o tema "O Movimento Antimanicomial como movimento social", discutiu o paradigma manicomial nas relações sociais, definindo como objetivo a extinção do manicômio, mas também o resgate do respeito, da cidadania e da subjetividade dos usuários (HENDRICH, 2007);

b) a elaboração de legislações estaduais tratando da questão da saúde mental referente à substituição progressiva de leitos em hospitais psiquiátricos por uma rede integrada de cuidado e atenção em saúde mental; ${ }^{13}$

c) a eclosão de diversas associações de usuários e familiares, e fortalecimento das que já haviam anteriormente sido constituídas (HENDRICH, 2007). ${ }^{14}$

Num cenário em que o Movimento da Reforma Psiquiátrica se consolidava, surgiu, como já supracitado na Introdução desse artigo, o Instituto Franco Basaglia como uma organização da sociedade civil, dentre tantas outras entidades, com o objetivo de contribuir para a consolidação dos paradigmas epistemológicos e assistenciais, em conformidade com as dimensões da Reforma. A seguir, apresentaremos o "Projeto éfeito de papel" como uma das possibilidades de inserção social e laborativa de usuários e familiares da rede de saúde mental por se tratar de uma oficina de promoção da geração de renda.

\footnotetext{
${ }^{13} \mathrm{Em}$ 1992, o estado do Rio Grande do Sul foi pioneiro em normatizar a assistência e práticas da saúde mental, seguido por Ceará em 1993; Pernambuco, em 1994; o Rio Grande do Norte, Minas Gerais, o Paraná e o Distrito Federal, em 1995; e, em 1996, o Espírito Santo (HENDRICH, 2007).

${ }^{14}$ Apesar de existirem algumas associações de familiares desde a década de 70, foi a partir da aprovação na Câmara do PL 3657/89 que se observou uma visível proliferação das mesmas. Primeiro porque, a partir da Sosintra, uma das mais antigas destas associações, que passou a apoiar o PL, outras seguiram o mesmo rumo e, outras ainda, foram constituídas com o mesmo objetivo (AMARANTE, 1997, p. 177).
} 


\section{"Projeto éfeito de papel": uma oficina em prol da geração de renda e da (re) construção da identidade social dos usuários da rede de saúde mental}

O Instituto Franco Basaglia - IFB, foi fundado em 1989, na cidade do Rio de Janeiro, por participantes do Movimento de Trabalhadores de Saúde Mental (MTSM/RJ). Portanto, um ano após a promulgação da Constituição Cidadã ${ }^{15}$, no mesmo ano da criação do PL Paulo Delgado e do retorno das eleições diretas para presidente. Essa organização, conforme apresentação em seu sítio eletrônico, define-se como:

(...) uma instituição civil sem fins lucrativos que atua na área da saúde mental e da reforma psiquiátrica no Brasil. (...)Seu principal objetivo é desenvolver ações estratégicas de incentivo à formulação de políticas públicas que possam resgatar os direitos de cidadania dos portadores de transtornos mentais. ${ }^{16}$

A entidade foi batizada com o nome do psiquiatra italiano Franco Basaglia, sob o lema "Cultura, informação e pesquisa para uma sociedade sem manicômios". Basaglia foi pioneiro da luta pelo fim dos manicômios e precursor do movimento de reforma psiquiátrica italiana, conhecida como Psiquiatria Democrática. O psiquiatra participou de alguns seminários e conferências no Brasil e influenciou substantivamente o movimento pela Reforma Psiquiátrica Brasileira, que constituiu suas ideias e ideologia, tendo-o como principal referência teórico-conceitual.

O IFB fundou-se, então, por militantes do MTSM, reunindo, sobretudo, profissionais da área da saúde, estudantes, usuários de serviços de saúde mental, pessoas com deficiência física e mental, familiares entre outros sujeitos que se inseriam no campo da saúde pública. O financiamento da instituição é operacionalizado por três vias: a) convênios firmados com as prefeituras municipais que buscam a assessoria técnica do IFB

\footnotetext{
${ }^{15}$ A Constituição Federal de 1988 foi chamada de Constituição Cidadã pelo deputado Ulysses Guimarães, $\mathrm{PMDB} / \mathrm{SP}$, fazendo referência ao fato de que houve intensa participação popular na elaboração do texto através dos movimentos sociais e entidades da sociedade civil.

${ }^{16}$ Disponível em: <http://www.ifb.org.br/sobre_ifb.php>. Acesso em 23 jun. 2014.
} 
para consolidar os serviços de Atenção Psicossocial, como nos Centros de Atenção Psicossocial - os CAPS $^{17}$; b) a oferta da formação de recursos humanos através de cursos de atualização e especialização na área da saúde mental; c) e, por fim, a contribuição associativa dos sócios do IFB recolhidas anualmente.

Sua composição institucional compreendia os cargos de Presidente, VicePresidente, Secretária Geral, Primeiro Secretário, Segundo Secretário, Tesoureira Geral, Primeira Tesoureira, Diretor do Núcleo de Pesquisa, Diretora do Núcleo Cultural e Diretor do Núcleo de Informações. É notório identificar que os diretores, em sua maioria, eram egressos tanto dos quadros do funcionalismo das universidades públicas, como professores e pesquisadores, quanto dos movimentos da Reforma Sanitária, das décadas de 70 e 80 .

As instalações da sede do IFB se localizavam em uma sala anexa ao Instituto Municipal Phillipe Pinel (IPP), no bairro de Botafogo, zona sul da cidade do Rio de Janeiro. O estabelecimento da sede deveu-se à assinatura de um Protocolo de Cooperação com o IPP, em 1992. É curioso destacar que a sede da entidade fica dentro das instalações de um hospital psiquiátrico, este "dispositivo"18 duramente criticado, que vem sendo ressignificado em sua concepção e modelo de assistência pela Reforma Psiquiátrica.

O Instituto Franco Basaglia, como uma entidade da sociedade civil, procurou assessorar entes estatais na direção de uma rede assistencial em saúde mental, reestruturando-a de acordo com os pressupostos da Reforma Psiquiátrica. Para tanto, suas atividades compreenderam convênios com órgãos públicos para prestação de

\footnotetext{
${ }^{17}$ Os Centros de Atenção Psicossocial - CAPS são serviços da Rede de Atenção Psicossocial voltados para a assistência diária a pessoas com transtornos mentais, reunindo uma equipe multiprofissional com médico/psiquiatra, psicólogos, assistentes sociais, enfermeiros, técnicos de enfermagem, terapeutas ocupacionais, musicoterapeutas, dentre outros. Os CAPS realizam o acompanhamento clínico e a reinserção social dos usuários do serviço pelo acesso às atividades laborais, artísticas e culturais fortalecendo os laços familiares e comunitários, na abrangência do território em que vivem. Este dispositivo busca envolver os usuários e familiares para a corresponsabilidade do tratamento e produção de autonomia, atento às demandas sociais da vida cotidiana.

${ }^{18}$ Nesse texto, os novos serviços de assistência à saúde mental, tais como o Centro de Atenção Psicossocial (CAPS), o Centro de Atenção Psicossocial Álcool e Drogas (CAPSad), o Núcleo de Assistência Psicossocial (NAPS), o Serviço de Residência Terapêutica (SRT), entre outros apresentados, funcionam como uma rede de saberes, práticas e técnicas em consonância com os paradigmas epistemológico e assistencial da RP, sendo apreendidos pelo conceito de "dispositivo" de Foucault (1999; 2000).
} 
assessoria, organização de encontros e congressos, elaboração de pesquisa, publicações acadêmicas, informação e divulgação na área de saúde mental. Também promovia atividades de cunho artístico e cultural em defesa dos direitos dos usuários de serviços de atenção à saúde mental, como novas formas de atendimento às pessoas em sofrimento psíquico, que podem ser resumidas nas seguintes diretrizes institucionais: ${ }^{19}$

1. O desenvolvimento de projetos que visem à construção, à ampliação e à consolidação de novos dispositivos de cuidados que substituam o modelo hospitalocêntrico;

2. A promoção de ações de defesa dos direitos dos usuários dos serviços de saúde mental e das pessoas portadoras de deficiência física e mental;

3. O desenvolvimento de ações de cultura e arte como processos potencializadores de cidadania, identidade e autonomia;

4. A difusão de informação, ensino e pesquisa no seu campo de trabalho.

Assim, o IFB, como entidade da sociedade civil, estabeleceu parcerias por meio de convênios com o Poder Público, sobretudo municipal, com vistas a consolidar o processo de institucionalização da Reforma Psiquiátrica por meio da assessoria técnica às secretarias e coordenações de saúde mental. Essa foi sua contribuição para construção de uma rede assistencial voltada para a reabilitação psicossocial dos pacientes psiquiátricos, conforme nos revela Rietra (1999).

O Instituto Franco Basaglia foi fundado em 1989, com o Projeto SOS Direitos do Louco, que prestava assessoria jurídica aos pacientes, com o objetivo de resgatar sua cidadania. Atualmente desenvolve trabalhos ligados à pesquisa, informação e cultura, além de dar suporte a projetos ligados aos direitos dos pacientes e a novas formas de tratamento. O IFB já havia assessorado programas de outros municípios, como Volta Redonda e Niterói. Segundo a Coordenadora de Programas do IFB, a escolha foi determinada pelo fato desta ONG já vir desenvolvendo um trabalho, seja de defesa de direitos do usuário, seja de fomento à pesquisa e de já vir pensando em contribuir de forma mais concreta para a transformação do modelo existente. (RIETRA, 1999, p. 69)

19 Disponível em: <http://www.ifb.org.br/sobre_ifb.php>. Acesso em 23 de jun. 2014 
Uma das principais contribuições do IFB no processo de institucionalização da Reforma foi fornecer a supervisão técnica, assegurando que os princípios preconizados pela Reforma Psiquiátrica fossem respeitados na via da parceria Estado-sociedade civil, conforme previsto na Constituição Federal. O IFB destacava-se também pelo desenvolvimento de projetos em interface com a arte, como "Alice prepara o gato!", "No centro da vida" voltado para a produção artística em oficinas de cinco CAPS da capital do Rio de Janeiro e um Hospital-dia, resultando em quatro edições de Mostras de Artes Visuais. O último projeto realizado pelo Instituto ${ }^{22}$ foi o "éfeito de papel”, com a implantação em alguns CAPS da cidade do Rio de Janeiro.

Sobre os CAPS, o movimento da Reforma Psiquiátrica os consideram como uma das formas possíveis para a transformação e a quebra do paradigma de "doença mental" para "saúde mental”. Os CAPS realizam o acompanhamento clínico e a reinserção social dos usuários do serviço pelo acesso às atividades laborais, artísticas e culturais fortalecendo os laços familiares e comunitários, na abrangência do território em que vivem. Nos termos de Foucault (1999; 2000), os CAPS, entendidos como um "dispositivo", buscam envolver os usuários e familiares para a corresponsabilidade do tratamento e produção de autonomia, atentos às demandas sociais da vida cotidiana. Com isso, além de mudar o modo de trabalho, busca-se também demarcar novas representações sociais acerca da identidade dos usuários dos serviços da rede de saúde mental, principalmente através das diversas oficinas que integram o cronograma de atividades oferecidas neste serviço.

As oficinas do “Projeto éfeito de papel: implantação de pólos de produção

\footnotetext{
${ }^{20} \mathrm{O}$ projeto "Alice, prepara o gato!" foi desenvolvido no CAPSAD da cidade de Niterói e oferecia aos usuários daquele serviço oficinas viabilizando o acesso à linguagem audiovisual e à aprendizagem de técnicas para produção de filmes.

${ }^{21}$ Informações sobre o projeto "No centro da Vida" foram obtidos através de entrevista com a antiga coordenadora técnica, em entrevista à pesquisadora e no sítio eletrônico: <http://www.ifb.org.br/cdavida/index.htm>.

${ }^{22}$ No mês de dezembro do ano de 2015, o evento intitulado "O Instituto Franco Basaglia-IFB: 1989 -2015", realizado no Instituto Phillip Pinel, anunciou oficialmente o encerramento das atividades do IFB, tendo este cumprido sua missão institucional de contribuir efetivamente "Por uma sociedade sem manicômios".
} 
artesanal na rede de saúde mental da Cidade do Rio de Janeiro" 23 , oferecidas em alguns CAPS da cidade do Rio de Janeiro, propunham-se a esse objetivo. O projeto foi desenvolvido pelo Instituto Franco Basaglia (IFB) submetido ao edital do Programa Desenvolvimento \& Cidadania Petrobras ${ }^{24}$ na seção de fomento à Geração de Renda e Oportunidade de Trabalho, sendo aprovado no ano de 2008. Realizou-se, então, pelo IFB, sob o patrocínio da Petrobras e em parceria com a Coordenação Municipal de Saúde Mental do Rio de Janeiro, Universidade Federal Rural do Rio de Janeiro (UFRRJ), Instituto Federal de Educação, Ciência e Tecnologia do Rio de Janeiro (IFRJ) ${ }^{25}$.

O "Projeto éfeito de papel" consistiu em implantar, nos Centros de Atenção Psicossocial localizados na zona norte e zona oeste da cidade do Rio de Janeiro, oficinas de produção de objetos artesanais em papel machê ${ }^{26}$. O objetivo do estabelecimento desses polos de produção era voltado para fins de comercialização das peças artesanais nos espaços de mercados de artesanato. Assim, haveria a promoção da geração de renda com a venda dessas peças, sendo os recursos revertidos aos usuários e familiares envolvidos no projeto. Nesta lógica, "Projeto éfeito de papel" atenderia, em parte, a uma das principais demandas desses atores: a inserção no mundo do trabalho.

As preferências dos participantes do projeto - usuários, familiares, técnicos e também de outras pessoas do serviço de saúde mental da região - em escolher que tipo de peça elaborar foram respeitadas e estimuladas, como parte do processo criativo, realizando-se em uma esfera de autonomia e liberdade. No entanto, muitas temáticas e

\footnotetext{
${ }^{23} \mathrm{O}$ acento na palavra efeito e a letra "f" em itálico foram propositais, segundo seus idealizadores. A ideia era usar o duplo sentido de efeito do papel tanto sobre as pessoas, quanto do ser feito de papel, ao mesmo tempo, frágil e forte.

${ }^{24}$ O Programa Petrobras Desenvolvimento \& Cidadania é uma iniciativa da estatal em promover projetos em parceria com entidades da sociedade civil e do governo para promover o desenvolvimento local, regional e nacional, sob a perspectiva da inserção social, digna e produtiva, de pessoas e grupos que vivem em vulnerabilidade social no Brasil.

${ }^{25}$ Ver CAMPOS, Giselli Avíncula. “Amassado, apertado e pincelado com as cores da primavera”: identidades em (re)construção em uma oficina de produção artesanal nos centros de atenção psicossocial. Dissertação (Mestrado em Ciências Sociais). Universidade Federal Rural do Rio de Janeiro - Seropédica, 2014.

${ }^{26} \mathrm{O}$ papel machê pode ser feito como massa feita com papel picado, amassado e esmagado, umedecido em água e misturado com cola, ou com tiras de papel coladas umas sobre as outras. Com ambas as técnicas é possível moldar objetos em diferentes formatos, utilitários ou decorativos. Nas oficinas do éfeito de papel eram utilizadas tiras de jornal embebidas na mistura de água e cola branca afixadas em objetos de materiais recicláveis como caixas de Tetra Pak, garrafas pet e todo tipo de material reutilizado.
} 
formas específicas, como os oratórios, foram sugeridas pelas monitoras ${ }^{27}$ das oficinas, e mesmo pelos artesãos, em vista da natureza dos eventos e a procura, dos compradores, por um tipo de peça nas feiras de artesanatos frequentadas pelos representantes do EP.

Também foram consideradas as limitações dos participantes das oficinas, enquanto sujeitos com interesses e potencialidades múltiplas e também como usuários da rede de saúde mental, que realizam acompanhamento clínico e uso contínuo de medicações que, em muitos casos, afetam o controle dos movimentos psicomotores.

Diante disso, o "Projeto éfeito de papel", idealizado para o campo da atenção psicossocial, considerou a perspectiva do trabalho coletivo de produção artística, em que todos os participantes poderiam e deveriam dar andamento e acabamento à confecção dos objetos, embora fosse assegurada a autonomia dos que desejassem, eles mesmos, iniciar e terminar uma única peça. Ou seja, o projeto visou garantir a participação daqueles com dificuldades motoras através do recurso à construção de peças coletivamente produzidas, mas também o trabalho individual, cujo autor produzisse a peça do início ao fim.

Como o "Projeto éfeito de papel" foi aprovado no edital do Programa Desenvolvimento \& Cidadania Petrobras no eixo de geração de Trabalho e Renda, logo os coordenadores do projeto, atentos à confecção, acabamento e recepção dos consumidores sobre as peças artesanais nos mercados artesanais, tentaram conciliar a dimensão mercadológica com foco no aprimoramento e venda dos produtos, e as considerações sobre a existência de sofrimento psíquico dos usuários com suas diferenciações motoras e de nível intelectual para que o objetivo do projeto fosse contemplado na dupla dimensão: geração de trabalho e renda e construção da autoestima e autonomia dos usuários e familiares da rede CAPS (ALMEIDA E REINHEIMER, 2012; 2014). Conforme dados obtidos durante o trabalho de campo, as peças melhor elaboradas artística e esteticamente eram posteriormente comercializadas

\footnotetext{
${ }^{27}$ Os monitores são aqueles - entre usuários, familiares, técnicos e demais pessoas da rede de saúde mental - que dominam e/ou assimilaram as técnicas do papel machê, dentre outras variações artísticas, tornandose habilitados a conduzirem os participantes das oficinas na aprendizagem e construção de peças artesanais feitas do material. No início do projeto, a monitoria fora realizada pelos coordenadores artísticos, multiplicadores e bolsistas dos cursos de graduação de Belas Artes, Economia Doméstica, Arquitetura do projeto de extensão da UFRRJ vinculado ao "éfeito de papel".
} 
em eventos de Economia Solidária ${ }^{28}$, feiras livres de artesanato e em ateliês do centro e zona sul da cidade do Rio de Janeiro.

Com intuito de atender às expectativas do projeto em suas várias dimensões, elencaremos seus desafios e estratégias: a) viabilizar a feitura e o término das peças que são construídas pela técnica do papel machê, que é simples, mas extremamente vagarosa na sua confecção; b) estabelecer uma rede de solidariedade entre os participantes, através do trabalho coletivo, na confecção artesanal dos objetos; c) sem transformar as oficinas em uma linha de montagem na lógica capitalista, estimular a produtividade sob à égide dos princípios da economia solidária para a geração de trabalho e renda; d) valorizar as potencialidades criativa, imaginativa e expressiva do usuário, através da interface da arte/artesanato, promovendo a autoestima, a autoconfiança, a autonomia dos partícipes do EP corroborando para o desenvolvimento das individualidades.

Nesse sentido, o "Projeto éfeito de papel" promove a (re)construção de novas identidades via produção e circulação de objetos artesanais. Reinheimer (2010), considerando o projeto do movimento Antimanicomial, destaca a reorientação das representações da "loucura" pela via da arte no processo de construção e reconstrução de identidades. Citemo-la:

O projeto político dos militantes da RP (Reforma Psiquiátrica) visa, em parte, a transformação do estigma do "louco", portanto uma mudança no estatuto dessa categoria. Nesse sentido, a unidade implícita na representação da loucura deveria ser substituída por uma diversidade, em grande medida amparada na produção artística e unificada em torno de uma identidade cultural e não sintomática/etiológica. (...) manifestações artísticas como recurso terapêutico e/ou de construção de identidades. (REINHEIMER, 2010, p. 57)

Portanto, neste trabalho percebemos algumas noções que conformam a identidade social dos usuários da rede CAPS, além de compreender a proposta da

\footnotetext{
${ }^{28}$ Sobre Economia Solidária, ver SINGER (2000; 2002), e sobre Economia Solidária e Saúde Mental, ver DELGADO (2005; 2014).
} 
dimensão sociocultural da Reforma ${ }^{29}$, por exemplo, que sob a perspectiva das expressões da arte e cultura, estimulam o exercício de um diálogo com a diferença, a fim de propiciar um novo sentido nas relações sociais entre usuários da rede de saúde mental e a sociedade e, por conseguinte, o reconhecimento de múltiplas formas de expressão individual e coletiva.

\section{Considerações Finais}

O movimento da Reforma Psiquiátrica brasileira organizou-se no sentido de rejeitar a violência asilar e os saberes e práticas centradas no hospital. Contudo, buscou redirecionar o dispositivo (FOUCAULT, 1997) que se constituiu em torno da "loucura", com o advento da Psiquiatria, para um novo paradigma: do tratamento da "doença mental" para a promoção da "saúde mental".

O processo de "desinstitucionalização" (ROTELLI, 1990, 1992), que consiste na crítica ao modelo manicomial para o cuidado em saúde mental e na reorientação dos conceitos, saberes, valores e práticas estabelecidas com relação à "loucura" na sociedade, caracterizou as ações do movimento da Reforma. A regulamentação da Lei 10.216/2001 e as inúmeras portarias ministeriais formalizaram a desconstrução da lógica e funcionamento do hospital psiquiátrico, para configurar uma rede de assistência à saúde mental sob a perspectiva do tratamento humanizado e inclusivo, integrando pessoas com "sofrimento psíquico" à sua rede familiar e comunitária, para o processo de reabilitação clínica e psicossocial.

O movimento da Reforma Psiquiátrica ampliou a discussão da consolidação de uma rede integrada de cuidado e atenção em saúde mental para o debate de iniciativas sensíveis às demandas sociais dos usuários e seus familiares como a garantia da autonomia e reinserção no mundo do trabalho, e mais ainda, reverter o estigma de periculosidade e "doente mental" para o reconhecimento de múltiplas individualidades,

\footnotetext{
${ }^{29}$ De acordo com Amarante e Costa (2012), a dimensão sociocultural da Reforma Psiquiátrica corresponde à transformação no imaginário social relacionado à loucura e ao louco. Sob a perspectiva da diversidade, a arte e a cultura são ressaltadas e direcionadas ao exercício de um diálogo com a diferença a fim de propiciar um novo sentido nas relações sociais entre usuários da rede de saúde mental e a sociedade.
} 
segundo a noção de alteridade, diferença e diversidade.

Dessa forma, pretendemos esboçar que iniciativas como o "projeto éfeito de papel" apontaram algumas possibilidades para o processo de construção social da identidade dos usuários da rede CAPS, assim como sugerir que as práticas artesanais desenvolvidas no EP podem ser válidas para pensar os seguintes apontamentos: as transformações do imaginário social das representações sociais acerca dos "sujeitos em sofrimento psíquico", a inserção do usuário em sua rede territorial, comunitária e laborativa, e por fim, as novas tecnologias do cuidado e assistência à saúde mental.

A capacidade de investir na criatividade configurando um "fazer artístico e artesanal" através do desenvolvimento das habilidades estéticas e do domínio das técnicas artesanais, permitiu potencializar a (re)construção social da identidade e as representações sociais sobre os usuários da rede de atenção psicossocial, bem como perceber como a proposta da dimensão sociocultural da Reforma Psiquiátrica - a transformação do imaginário social relacionado à "loucura" - e os sentidos atribuídos à arte na saúde mental estão sendo desenvolvidos.

\section{Referências}

ALMEIDA, Neli; REINHEIMER, Patricia. A Capa: éfeito de papel. In: AMARANTE, Paulo. NOCAM, Fernanda. (Org.). Saúde mental e arte: práticas, saberes e debates. $1^{\text {a } e d . ~ S a ̃ o ~}$ Paulo: Zagodoni, 2012.

ALMEIDA, Neli; REINHEIMER, Patricia. Atenção psicossocial e artesania: a história do projeto éfeito de papel. Rio de Janeiro: Folha Seca, 2014.

AMARANTE, Paulo. (Coord.). Loucos pela vida: a trajetória da reforma psiquiátrica na Brasil. Rio de Janeiro: FIOCRUZ, 1995 .

AMARANTE, Paulo. Novos sujeitos, novos direitos: O debate em torno da reforma psiquiátrica. Cadernos de Saúde Pública, v.11, n.3, p.491-494, 1995 b.

AMARANTE, Paulo. Loucura, cultura e subjetividade: conceitos e estratégias, percursos e atores da reforma psiquiátrica brasileira. In: FLEURY, Sonia (Org.) Saúde e democracia: a luta do CEBES. São Paulo: Lemos Editorial, 1997. 
AMARANTE, Paulo; COSTA, Ana. Diversidade cultural e saúde. Rio de Janeiro: Cebes, 2012.

BECKER, Howard Saul. Outsiders: estudos de sociologia do desvio. Rio de Janeiro: Zahar, 2008.

BEZERRA JR, Benilton. O sentido da arte na atenção à saúde mental: considerações sobre o cenário pós-manicomial. In: MELO, Walter; FERREIRA, Ademir Pacelli (Orgs.). A sabedoria que a gente não sabe. Rio de Janeiro: Espaço Artaud, 2011.

CAPONI, Sandra. Michel Foucault e a Persistência do Poder Psiquiátrico. Ciência \& Saúde Coletiva, v. 14, n. 1, p. 95-103, jan./fev., 2009. Disponível em:

<http://www.scielo.br/pdf/csc/v14n1/a15v14n1.pdf>. Acesso em 17 jun. 2014.

FLEURY, Sonia. A questão democrática na saúde. In: FLEURY, Sonia (Org.), Saúde e Democracia: A Luta do CEBES. São Paulo: Lemos Editorial, 1997.

FOUCAULT, Michel. Vigiar e punir. Petrópolis: Vozes, 1977.

FOUCAULT, Michel. Resumo dos cursos do Collège de France (1970-1982). Rio de Janeiro: Jorge Zahar, 1997.

FOUCAULT, Michel. História da sexualidade I: a vontade de saber. Rio de Janeiro: Graal, 1999.

FOUCAULT, Michel. Sobre a história da sexualidade. In: FOUCAULT, Michel. Microfísica do poder. Rio de Janeiro: Graal, 2000.

FOUCAULT, Michel. El poder psiquiátrico. $1^{\mathrm{a}}$ ed. $1^{\mathrm{a}}$ reimp. Buenos Aires: Fondo da Cultura Económica, 2007.

FOUCAULT, Michel.História da loucura na idade clássica. $9^{a}$ ed. São Paulo: Perspectiva, 2010.

GOHN, Maria da Glória. História dos movimentos e lutas sociais: a construção da cidadania dos brasileiros. São Paulo: Loyola, 1995.

GOSS, Karine Pereira; PRUDENCIO, Kelly. O conceito de movimentos sociais revisitado.

Revista Eletrônica dos Pós-Graduandos em Sociologia Política da UFSC/ EmTese, v. 2, n. 1, p. 75-91, 2004. Disponível em :

<https://periodicos.ufsc.br/index.php/emtese/article/view/13624/12489>. Acesso em 19 jun. 2014. 
HEIDRICH, Andréa Valente. Reforma psiquiátrica à brasileira: análise sob a perspectiva da desinstitucionalização. 2007. Tese (Doutorado em Serviço Social) - Pontifícia Universidade Católica do Rio Grande do Sul, Porto Alegre, 2007.

LACLAU, Ernesto. Os novos movimentos sociais e a pluralidade social. Revista Brasileirade Ciências Sociais, São Paulo, SP, v. 1, n. 2, p. 41-47, out. 1986.

MARX, Karl. Para a Crítica da Economia Política. Tradução de Edgard Malagodi, Leandro Konder, José Arthur Giannotti, Walter Rehfeld. São Paulo: Abril Cultural, 1982.

REINHEIMER, Patricia. Tô maluco, mas tô em obra: a trajetória do artista moderno e as representações da loucura. Revista de Ciências Sociais, Fortaleza, CE, v. 41, n. 1, p. 48-66, jan./jun., 2010. Disponível em: <http://www.rcs.ufc.br/edicoes/v41n1/rcs_v41n1a4.pdf>. Acesso em 13 fev. 2012.

RIETRA, Rita de Cássia Paiva. Inovações na gestão em saúde mental: um estudo de caso sobre o CAPS na cidade do Rio de Janeiro. 1999. Dissertação (Mestrado em Saúde Pública) - Fundação Oswaldo Cruz, Escola Nacional de Saúde Pública, Rio de Janeiro, 1999.

ROTELLI, Franco. A instituição inventada. In: NICÁCIO, Maria Fernanda de Silvio. (Org.). Desinstitucionalização. São Paulo: Hucitec, 1990.

ROTELLI, Franco. A experiência da desinstitucionalização italiana: o processo Trieste. Saúde Debate, n.2, jun. 1992. (Cadernos Polêmicos).

TENÓRIO, Fernando. A reforma psiquiátrica brasileira, da década de 1980 aos dias atuais: história e conceito. História, Ciências, Saúde. Manguinhos, Rio de Janeiro, v. 9, p.25-59, jan.-abr. 2002. Disponível em: <http://www.scielo.br/pdf/hcsm/vgn1/a03v9n1.pdf>. Acesso em 17 fev. 2012. 